\title{
Audit of Auditoriums in an Academic Setting, Ghana
}

\author{
Christian Koranteng1, Barbara Simons ${ }^{2}$, Selorm Fiati ${ }^{1}$ \\ ${ }^{1}$ Department of Architecture, Kwame Nkrumah University of Science and Technology, Kumasi, Ashanti Region, Ghana \\ ${ }^{2}$ Department of Construction Technology and Management, Kwame Nkrumah University of Science and Technology, \\ Kumasi, Ghana \\ Email: nanaakuaayebea@yahoo.co.uk
}

How to cite this paper: Koranteng, C., Simons, B. and Fiati, S. (2019) Audit of Auditoriums in an Academic Setting, Ghana. Journal of Building Construction and Planning Research, 7, 99-114. https://doi.org/10.4236/jbcpr.2019.74007

Received: May 13, 2019

Accepted: November 13, 2019

Published: November 26, 2019

Copyright $\odot 2019$ by author(s) and Scientific Research Publishing Inc. This work is licensed under the Creative Commons Attribution International License (CC BY 4.0).

http://creativecommons.org/licenses/by/4.0/ (c) (i) Open Access

\begin{abstract}
Auditorium buildings are special structures needing much attention for it to function properly. Generally, consideration should be given to seating, sightlines, and acoustic requirements. In addition, the design should ensure performer-audience intimacy as much as possible. The focus of the study is to review design strategies for auditoria on the Kwame Nkrumah University of Science and Technology, Kumasi campus towards compliance and to develop solutions for improvements that will enhance the performance of 4 selected auditorium facilities. Case study, observation and measurements were the main strategies used. The results revealed that the approaches involved in auditorium designs are shape, volume, surface boundary dimensions and materials, stage, seating, foyers and sightlines. These parameters are grouped under acoustical, functional and programmatic parameters. Reverberation time calculated was high which indicated speech intelligibility problems, hence, improvement efforts were made to change the floor materials from polished tiles to carpeted floors, and high absorption wall claddings. In the process, the reverberation time was reduced from $1.47-2.23$ to $0.84-1.73$ for the studied buildings. The study recommends strict adherence to standards and guidelines, and for designers to have a keen focus on designing these special buildings. A renovation effort when undertaken, will lead to improvements in the performance of the selected buildings.
\end{abstract}

\section{Keywords}

Design Strategies, Speech Intelligibility, Reverberation Time, Acoustics, Simulation

\section{Introduction}

In recent times, important events such as conferences and concerts take place in 
enclosed spaces [1]. These enclosed spaces classified as auditorium facilities are purposely built halls for audition [2]. According to the Whole Building Design Guide Staff [3] auditorium facilities are used for large meetings, presentations, and performances. These facilities may include assembly halls, exhibit halls, and theatres.

\subsection{Research Objectives}

The study has the following objectives:

1) To investigate the strategies involved in auditoria design,

2) To audit selected auditorium buildings in an educational setting towards compliance to accepted strategies.

\subsection{Auditorium Design}

"Auditorium design begins with the loudspeaker and how it plays sound into the hall. It ends with how the hall returns reflections of the sound back to the audience" [2]. As such, the auditorium design criteria suggested by [4] includes the following;

- Ensuring very low background noise from external and internal sources;

- Sound produced must be reasonably loud;

- Providing appropriate reverberation time; and

- Avoiding acoustical defects such as echoes, long-delayed reflections and sound shadows as shown in Figure 1.

Echo (Figure 1) is the delay in receiving sound from multiple reflections and producing confusing sound [5]. To prevent the occurrence of echoes, sound absorbing materials can be installed along the reflective surfaces producing this defect [6].

Similar views have been supported by [7] but according to the author, architectural considerations such as shape, dimensions, volume, layout of boundary surfaces, seating arrangements and audience capacity, affect hearing conditions in any auditorium. Figure 1 demonstrates acoustical flaws in auditorium buildings.

In order to achieve optimum acoustics in educational facilities, it is important to consider reducing background noise and the reverberation time. According to [8], several works have been carried out on standard reverberation time for various spaces. Thus, authors have suggested recommendations for reverberation

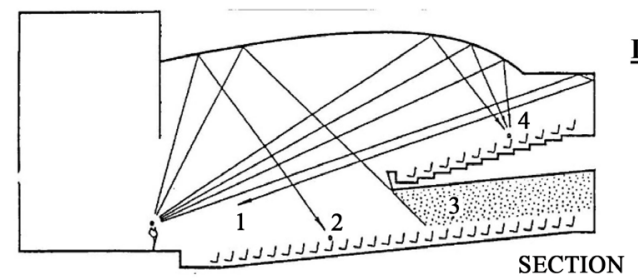
Defects
1. Echo
2. Long-delayed reflection
3. Sound shadow
4. Sound concentration

Figure 1. Acoustical defects in Auditorium (https://karagioza.wordpress.com/2014/04/14/reflection/). 
time as a fixed number independent of the room volume while other authors recommend reverberation times as a fixed number for a range of room volumes. Unlike the first two schools of thought, there is a third school of thought that suggests reverberation time as dependent on the room volume using formulae [9]. For Spoken word and amplified music, recommended optimum Reverberation Time (RT) is given by [10] as a function of the room volume as shown in Table 1 and Table 2.

[10] again highlights that for multipurpose auditoria, reverberation time may not be enough for music, but may be excessive for spoken word. [11] in a review of acoustical standards in the design of school spaces agrees with [10] that the reverberation time could be compromised to $1 \mathrm{~s} \pm 10 \%$. However, [10] introduces the role of active acoustics (the use of microphones, loudspeakers and signal processing) to vary reverberation time than will be possible with just passive variable acoustics. Therefore, active acoustic systems give the potential for a speech- oriented hall to be used for music performances.

As suggested by [3], [12], and [13] careful attention should be given to seating, sightlines, and acoustic requirements. In addition, the design should ensure performer-audience intimacy as much as possible. All these factors are grouped into acoustical, functional, and programmatic parameters [14].

\subsubsection{Acoustic Parameters}

According to [13] and [14] the requirement to achieve good acoustical conditions should be the principal determinant of the geometrical form. For instance, [15] observed that concave, round shapes, including parabolic walls, and domed ceilings are the worst shapes for a room in which speech is important. [7] include the shape or form, volume, and dimensions of the hall as important criteria to consider during the design of auditoria. Concerns on the form, volume, and dimensions of the auditorium being addressed at an early stage during design are also expressed by [16]. Noteworthy is the shape, volume and characteristics of the boundary surfaces in determining the acoustic qualities based on the reverberation time, sound strength and intelligibility [17].

\section{Shape}

The internal shape of an auditorium is considered to ensure audience visibility of the stage [18]. Examples of hall shapes include the following:

Table 1. Optimal Reverberation Time (RT) for spoken word.

\begin{tabular}{ccccc}
\hline Volume $\left(\mathrm{m}^{3}\right)$ & 1000 & 5000 & 10,000 & 20,000 \\
\hline RT & 0.7 & 0.8 & 0.85 & 1.1 \\
\hline
\end{tabular}

Table 2. Optimal Reverberation Time (RT) for amplified music.

\begin{tabular}{ccccc}
\hline Volume $\left(\mathrm{m}^{3}\right)$ & 1000 & 2500 & 5000 & 6500 \\
\hline RT & 0.65 & 0.8 & 1.05 & 1.2 \\
\hline
\end{tabular}


- Rectangular (shoebox-type) hall: According to [7], this type of hall shape is suitable for music halls and small speech halls. [18]further suggests that in the rectangular shaped hall, reflectors could be used to direct sound to the rear of the hall and absorbers could be used to reduce reflections.

- Wide fan: Normally used in modern hall design and can accommodate large volume of occupants. It gives a better view of stage and a good sound [18]. However, this plan shape is not suitable for music performances [7].

- Raked seats. Normally found in cinema theatres with straightforward designs. Even though it has good audience seating, it provides less sound quality [18].

According to [7], sidewalls should be splayed from stage which allows a greater seating capacity relatively close to the stage. A sidewall splay may range from $30^{\circ}$ to $60^{\circ}$ and useful to reflect sound to the rear halls. Other forms of shape include diamond and horseshoe. The worst shape for a hall is a cube because all three surfaces resonate with the same frequencies [7].

\section{Volume}

The auditorium must be shaped to ensure the audience is closer to the speaker [19]. [20] recommends that the air volume per spectator should be $4-5$ for playhouses and $6-8$ for opera halls. [5] however, suggests that "the ratio of auditoriums length, width, and height are the simplest and most effective tool for achieving good acoustic results". [7] concurs with [5] by giving the ratios 1:1.14:1.39 as the minimum ratio of height to width to length, and the maximum being 1:1.60:2.33. Generally, the larger the volume, the longer the reverberation time, this creates echoes in the space.

\section{Boundary surfaces and dimensions}

- Floor. According to [21] and [22], the floor design should be flexible enough to accommodate variable seating and acoustic requirements. In addition, even though carpet is often used, timber floors offer better acoustics. The [3], is of the view that "sloped floors, with level terraces for each row of seating provides proper sight and sound lines from the audience to the stage". The floor of an auditorium should have a minimum slope of $8^{\circ}$ whilst that of a lecture-demonstration hall is $15^{\circ}$ [7]. [23] opine that in auditorium spaces that have only vertical walls, the main surface where sound absorption is predominantly concentrated is the floor. Timber floors offer better acoustical performance as compared to ceramic tiles and concrete floors. For example, at a frequency of $500 \mathrm{~Hz}$, heavy carpet on screed or concrete floors also absorbs $0.14 \mathrm{~dB}$ of sound as compared to ceramic tiles of $0.01 \mathrm{~dB}$.

- Ceiling: [24] explains that both the wall and ceiling should be shaped to direct sound to the seating areas of the auditorium. It is essential that smooth ceilings are not made parallel to the floors to avoid echoes [7]. [22] is also of the view that high ceilings are suitable for concerts, musicals, and opera halls whilst lower ceilings are used for drama and speech halls.

- Wall: Regarding the views of [7], [15], and [24], concave, round, parabolic wall shapes, domed, barreled and cylindrical ceilings must be avoided be- 
cause of the undesirable sound foci they create making some areas louder than other parts. [7] further explains that the ceiling height is dependent on the overall room volume and should be about one-third to two-thirds of the room width. On the contrary, [24] suggests that in auditorium design, the recommended ceiling height should be between $8-12 \mathrm{~m}$ to ensure useful sound reflections by the ceiling. [12] also proposes a ceiling height of $13 \mathrm{~m}$ for a hall without gallery but with a fully covered floor area by the audience and performers.

- Gallery: Galleries can be used to increase seating capacity and reduce the distance of the farthest row of seats from the stage [19]. [22] suggests that the angle of the sightline from the balcony to the stage should not exceed $30^{\circ}$. [23] explains that there should be enough free height between the audience beneath the gallery and the gallery ceiling. Also, the depth of the seating beneath the gallery should not exceed twice this height. [22] recommends a depth to height ratio for galleries in concert halls to be $1: 1$, whilst that for opera and drama is to be $2: 1$. [6] and [7] further explain that deep galleries can create acoustical shadows. Moreover, the front of the gallery parapet should be designed to avoid reflections that would affect the sound quality.

\subsubsection{Functional and Programmatic Parameters}

According to [14], functional parameters consist of anthropometric constraints such as sightlines and conditions for visual clarity. Programmatic parameters deal with the dimensions of the stage and seating area, type of performance to take place in the auditorium and the capacity of the auditorium. The following explains some of these functional and programmatic parameters required in auditorium design.

\section{Sightlines}

It is necessary for the section and plan of an auditorium to meet certain requirements regarding vertical and horizontal sightlines [22]. [7] and [20] propose that the minimum eye height should be $1100 \mathrm{~mm}$. On the contrary, the average eye height according to Appleton et al. (2008) should be $1120 \mathrm{~mm}$. [22] further states that the eye height should be $1120 \pm 100 \mathrm{~mm}$.

\section{Seating}

Generally, the seating layout is straight or curved and focused towards the stage or platform [21]. [22] also suggests that the seating layouts could be straight, straight with curved ends, curved, angled or straight rows in blocks at different angles. Likewise, [25] asserts that the seat surfaces in auditorium are the most important absorption surface in the main hall of auditoria, since the surface of the seats is by large the most important sound absorbing surface in the main hall.

\section{Stage}

[21] describes the stage as the main performance area and its associated side and rear spaces. [22] classifies the stage into different types such as proscenium, thrust, and open stages. To add to this, [21] gives five variations for the open 
stage formats as follows: end stage, fan-shaped, thrust stage, theatre-in-the-round, and transverse stage. The author also states that for a raised stage, the height should be between $600 \mathrm{~mm}$ and $1100 \mathrm{~mm}$ and could have a straight, angled, or curved front edge.

\section{Foyers}

[26] is of the view that an entrance lobby must be provided and ought to be designed such that at least $50 \%$ of the audience will be able to exit though it since it serves as the main entry and exit point. Furthermore, the lobby serves as a circulation space, selling refreshments, and displaying information. [24] proposes that lobby areas should be at least one-third of the total auditorium seating area.

Literature reviewed shows that acoustical, functional and programmatic parameters influence key indicators of sound intelligibility such as the reverberation time, sound strength and speech clarity. This paper focuses on evaluating the acoustic characteristics/qualities in terms of the afore-mentioned parameters of selected auditoria. Moreover, the influence of the acoustic, functional and programmatic design parameters is reviewed to provide improvement to the selected buildings.

\section{Research Methodology}

The empirical location for the study is Kwame Nkrumah University of Science and Technology (KNUST) campus in Kumasi, Ghana. The strategy adopted for the study included observation and case studies.

\subsection{Research Strategy}

The main strategy used was case studies. Four (4) cases all located on KNUST campus in Kumasi were purposively sampled for the study. The facilities selected are the KNUST School of Business auditorium, known as the Saarah-Mensah auditorium (KSB), College of Engineering auditorium (CE), the Great Hall (GH) and the Evans Anfom auditorium (CCB). These facilities form $90 \%$ of existing auditoria at KNUST and it is imperative to find out the strategies applied in their designs towards compliance and to suggest improvements for their performance.

\subsection{Data Collection Tools}

\section{Objective Measurement:}

Objective measurements were carried out in all the cases using a surveyors' tape and infrared measuring tools to have an idea of the spatial and seating provisions in the selected facilities.

\section{Observation:}

Observation was useful in documenting activities and physical aspects such as the layout and the design strategies used in the selected cases. The observation carried out was done with the aid of a prepared guideline. The guideline was on shape and form of the auditorium, volume, and materials used, characteristics of 
the stage area, seating area, and foyer.

\section{Simulation:}

The reverberation time was calculated manually using the Sabine's Formula,

$$
T=0.16 \times V / A
$$

where " $T$ " is the reverberation time, " $V$ " is the volume of the space in cubic meters and " $A$ " is the total absorption (absorption coefficient of the boundary surfaces $\mathrm{x}$ surface area) as cited in [17].

The Reverberation time for the various auditoria studied was again calculated using the Saint Gobain Ecophon room acoustic calculator software (simulator) and the results were compared to the manually calculated values.

Notable is that the Ecophon acoustic calculator does not have multipurpose halls as a category for the room types. The closest option was lecture theatre, conference room and music room. Meanwhile, the auditoria studied were mostly multi-purpose halls for both music, concerts, conferences, and in the case of the Great Hall, music, concerts, conferences, dinner, and other ceremonies. Hence, the engineering auditorium was assumed to be a conference room. The KSB auditorium was taken to be a lecture theatre, the Great Hall a music room and the CCB auditorium a conference room.

In addition to the above, the Ecophon acoustic calculator has default ceiling systems and as a result, choices were made on best fit for the various auditoria. For the CE, CCB and GH auditoriums the "Ecophon Flexiform A $30 \mathrm{~mm}$ " was selected as ceiling systems, and for the KSB, "Ecophon Master Matrix" was used.

\subsection{Data Analysis}

Data obtained was analysed and compared to the codes and standards derived from the literature reviewed. This brought to light the strengths and weaknesses of the facilities to be able to develop solutions that will enhance auditorium designs both in the present and in the foreseeable future.

\subsection{Description of Case Studies}

\subsubsection{The College of Engineering Auditorium (CE)}

The Engineering auditorium has a gross floor area of $564 \mathrm{~m}^{2}$ and a capacity of 870. It serves as a lecture hall, an auditorium for music concerts, conferences and other ceremonies. Figure 2 and Figure 3 show images of the auditorium and Table 3 illustrates the acoustics parameters.

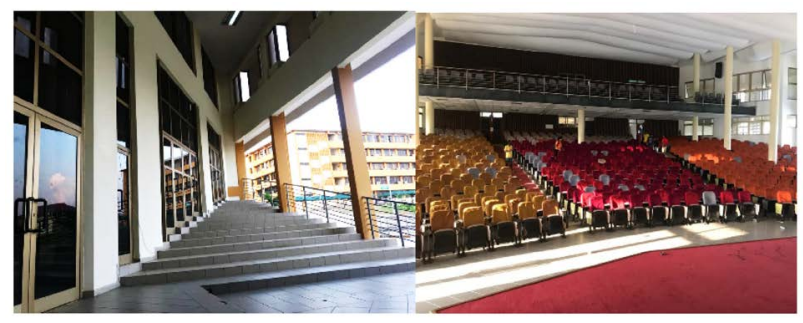

Figure 2. Interior and exterior views of CE. 
Table 3. Acoustic, functional and programmatic characteristics of Engineering auditorium.

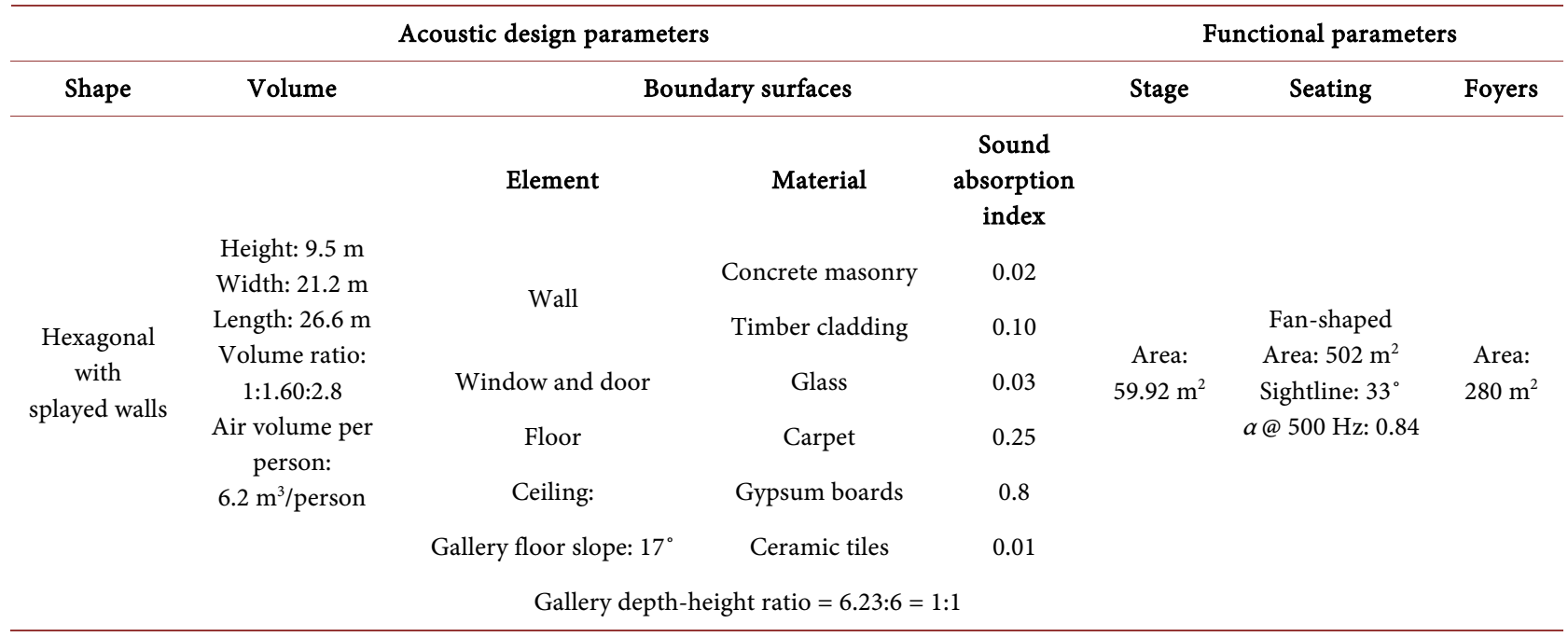

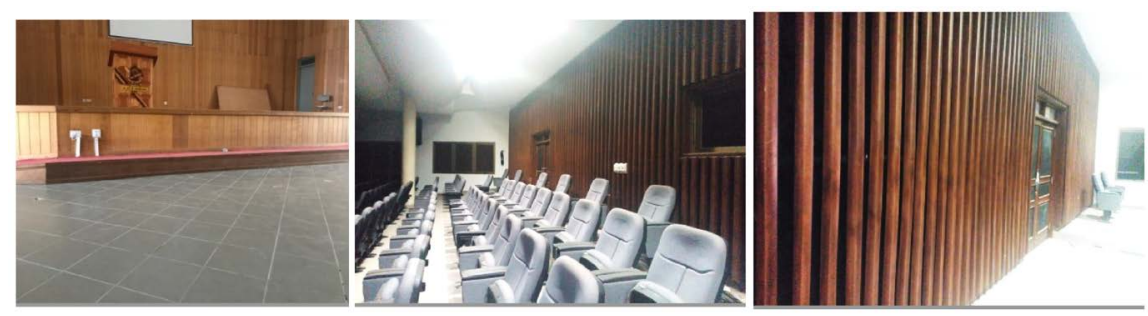

Figure 3. Images of timber cladded walls at the stage and gallery.

\subsubsection{Saarah-Mensah Auditorium (KSB)}

The Saarah-Mensah auditorium was designed for teaching, learning and research in the business school with a seating capacity of 950. Detailed descriptions of the facility are shown in Figure 4 and Figure 5 and Table 4 . The effect of these high reflectance coefficient materials results in poor performance of the space.

\subsubsection{The Great Hall (GH)}

This auditorium was designed as a multi-purpose hall and hence, it has a more generalized and flexible layout with a capacity of 1600. Figure 6 and Table 5 show the details of the facility.

\subsubsection{Evans Anfom Auditorium (CCB)}

The Evans Anfom Auditorium has served as a multipurpose auditorium facility holding programs such as conferences, lectures, graduation ceremonies, musical and drama shows. It has a total seating capacity of 1200 . Detailed descriptions of the facility are shown in Figure 7 and Table 6.

\section{Results and Discussion}

\subsection{Shape}

The internal shape of an auditorium is considered to ensure audience visibility 
Table 4. Acoustic, functional and programmatic characteristics of KSB auditorium.

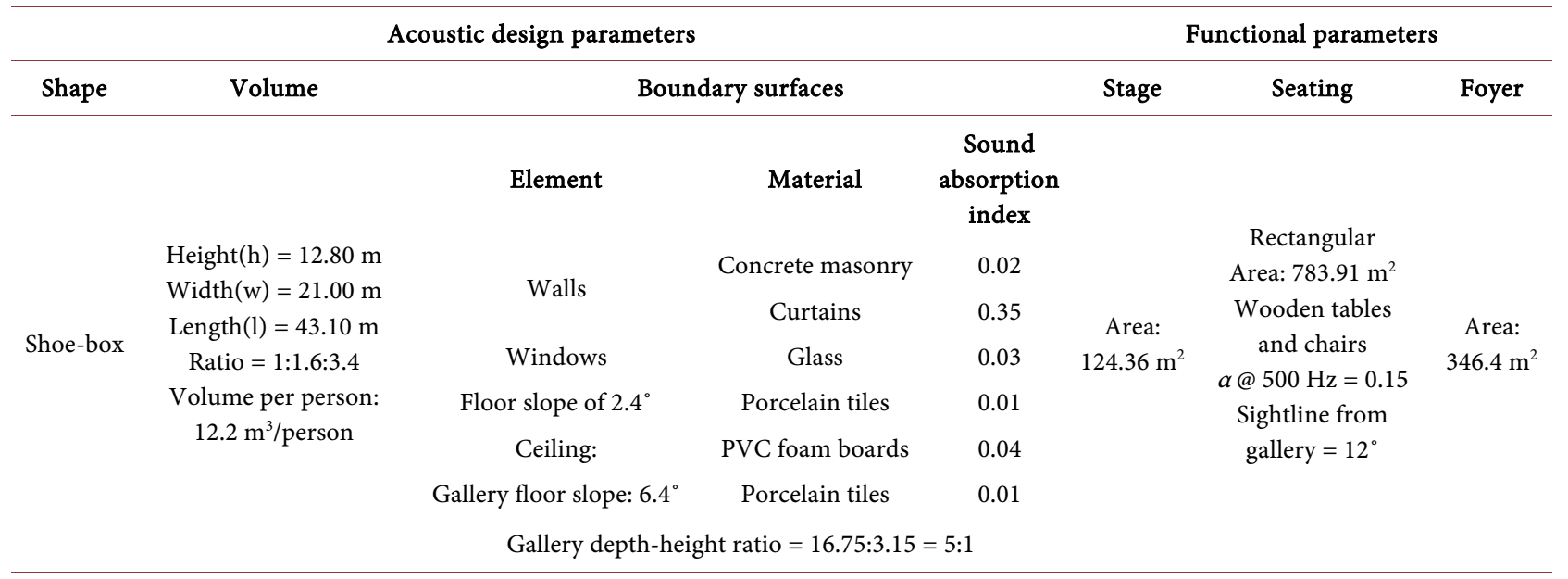

Table 5. Acoustic, functional and programmatic characteristics of the Great Hall.

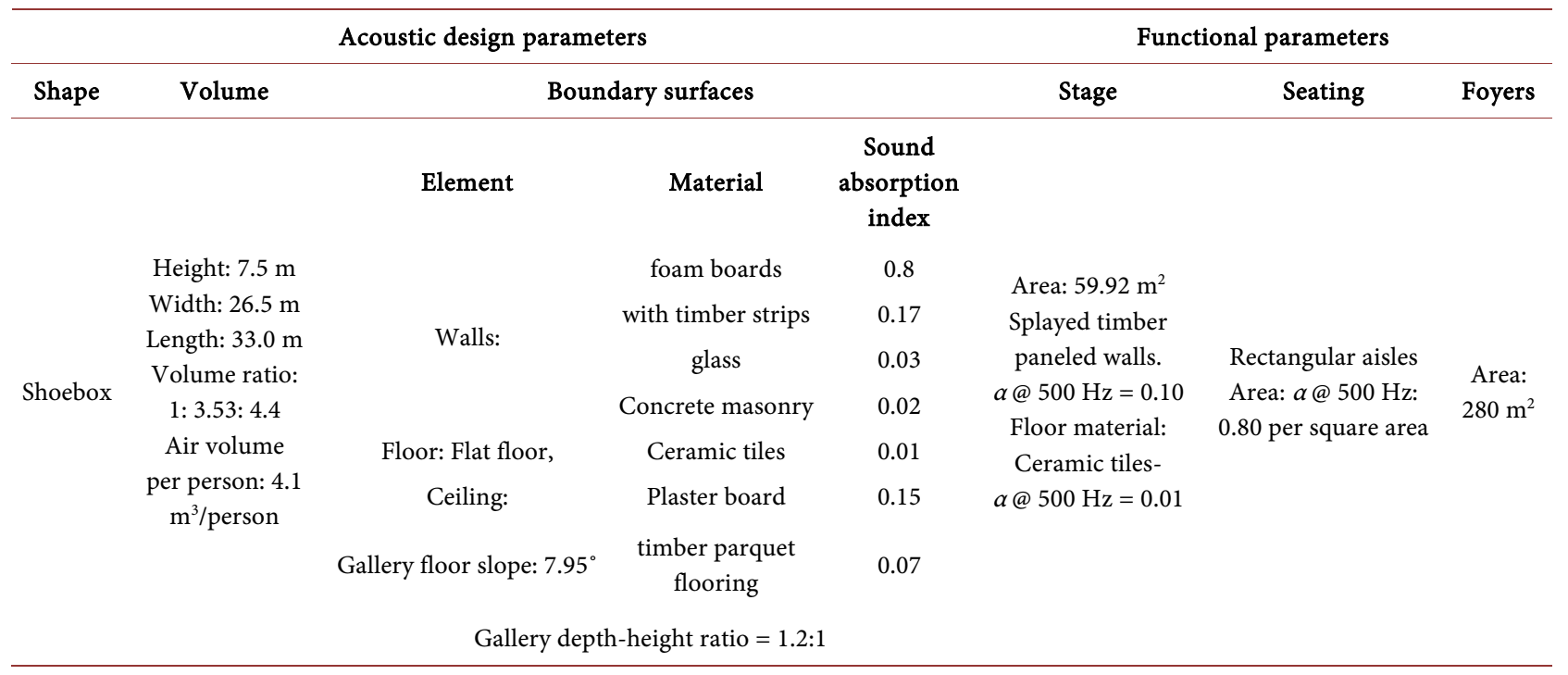

Table 6. Acoustic, functional and programmatic characteristics of CCB auditorium.

\begin{tabular}{|c|c|c|c|c|c|c|c|}
\hline \multicolumn{5}{|c|}{ Acoustic design parameters } & \multicolumn{3}{|c|}{ Functional parameters } \\
\hline Shape & Volume & & ndary surfaces & & Stage & Seating & Foyers \\
\hline $\begin{array}{c}\text { Rectangular } \\
\text { with Splayed } \\
\text { sidewalls at } 8^{\circ}\end{array}$ & $\begin{array}{c}\text { 10,898.1 m³ } \\
\text { Height: } 13 \\
\text { Width: } 21.2 \mathrm{~m} \\
\text { Length: } 46.9 \mathrm{~m} \\
\text { Ratio of height: } \\
\text { width: length = } \\
\text { 1:1.66:3.61 } \\
\text { Air volume } \\
\text { per person: } \\
9.1 \mathrm{~m}^{3} / \text { person }\end{array}$ & $\begin{array}{c}\text { Walls Perimeter: } \\
285.99 \mathrm{~m} \\
\text { Windows } \\
\text { Floor } 4.8^{\circ} \\
\text { Ceiling: } \\
\text { Gallery floor slope: } \\
9.5^{\circ}\end{array}$ & $\begin{array}{c}\text { Concrete } \\
\text { masonry } \\
\text { Glass } \\
\text { Porcelain tiles } \\
\text { Gypsum boards }\end{array}$ & $\begin{array}{l}\text { Sound } \\
\text { absorption } \\
\text { index }\end{array}$ & \multirow[t]{2}{*}{$\begin{array}{c}\text { Area: } 98.8 \mathrm{~m}^{2} \\
\text { Stepped } \\
\text { seating at } 4.8^{\circ} \text {. } \\
\text { height of } 450 \mathrm{~m}\end{array}$} & \multirow[t]{2}{*}{$\begin{array}{c}\text { Area: } 739.5 \mathrm{~m}^{2} \\
\text { Fixed Seating, } \\
\text { Raked floors }\end{array}$} & $581.5 \mathrm{~m}^{2}$ \\
\hline & & Gallery $\mathrm{c}$ & pth-height ratio $=$ & & & & \\
\hline
\end{tabular}




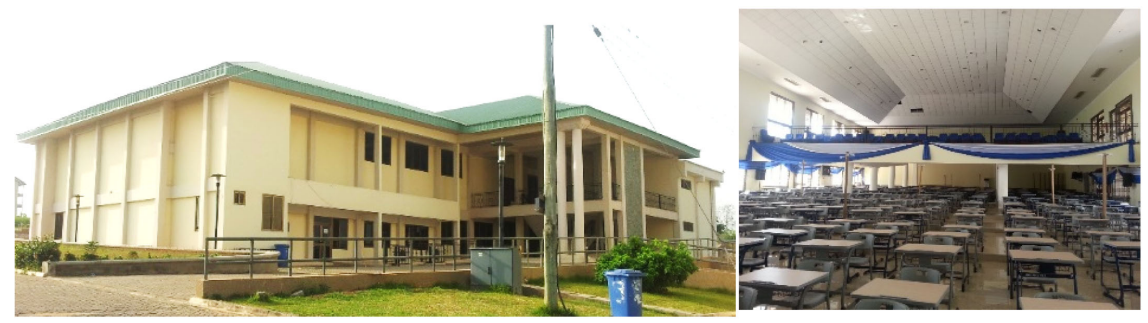

Figure 4. Exterior and interior images of the KSB auditorium.

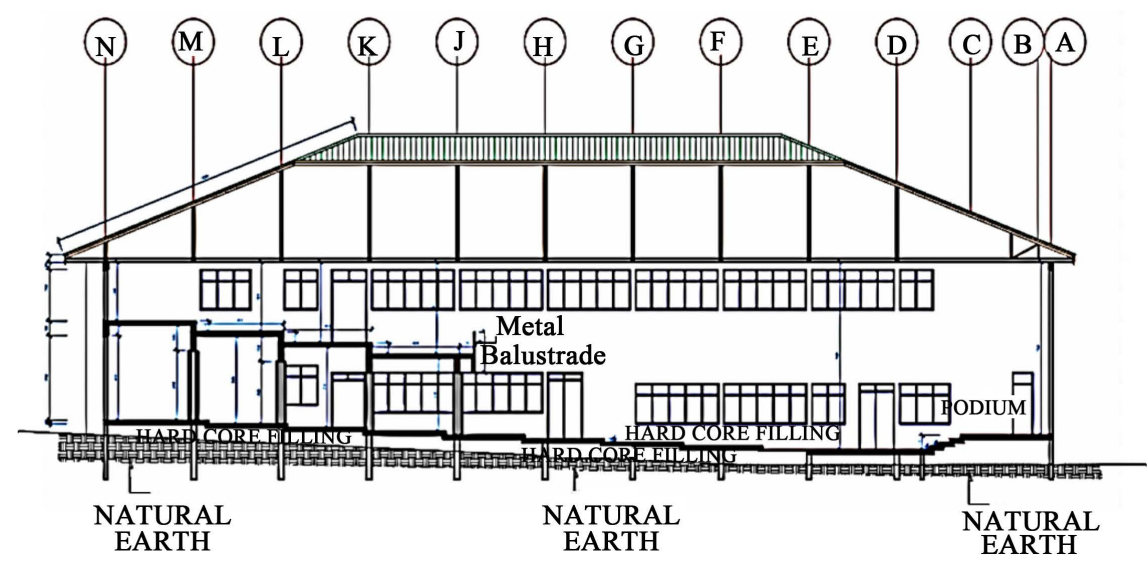

Figure 5. Sectional view of the KSB auditorium.
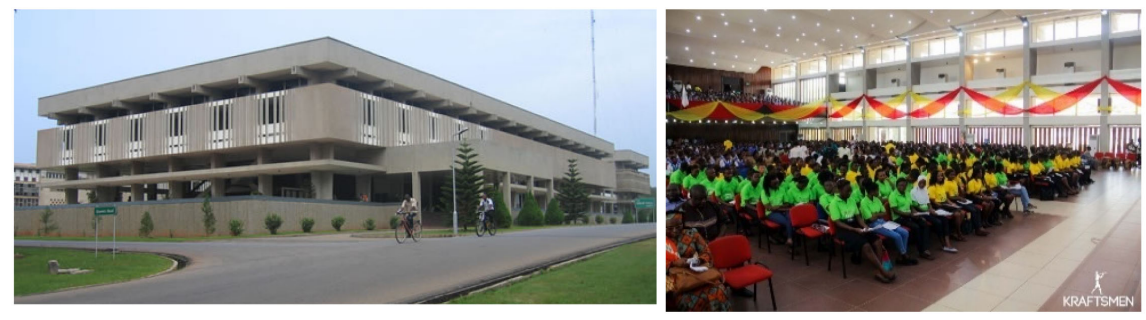

Figure 6. Exterior and interior images of the Great Hall.
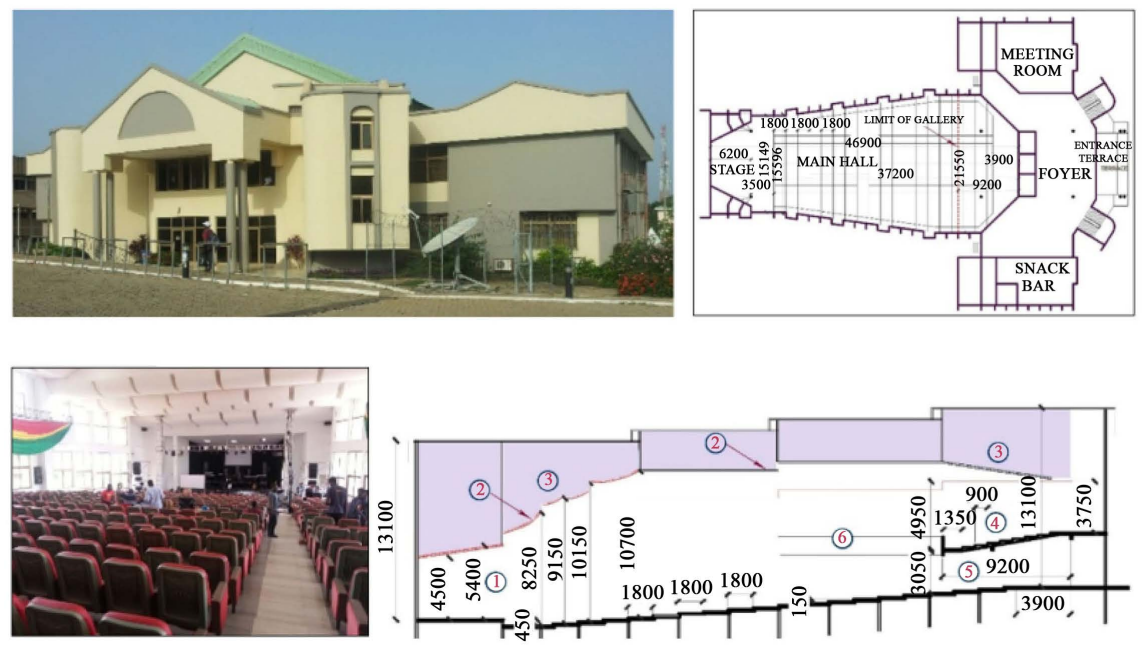

Figure 7. Exterior and interior images of the CCB auditorium with its plan and section. 
of the stage and effective sound distribution to the audience [18]. The CE auditorium and the CCB auditorium both had a hexagonal shape. The side walls are splayed as recommended by [7]. However, the side walls of the CCB auditorium were splayed at an $8^{\circ}$ angle which is less than the $30^{\circ}-60^{\circ}$ angle recommended by [7]. Hence, the purpose of ensuring useful sound reflections may not be achieved as accurately as predicted in the CCB auditorium. The KSB and GH auditoriums both have a shoebox shape, ideal for music and small speech halls.

\subsection{Volume}

The volume of an auditorium is a key determinant of the quality of sound in an auditorium. According to [27], the air volume per person is a primary indicator for speech quality. For speech-oriented rooms or auditoria, the recommended volume $\left(\mathrm{m}^{3}\right) /$ per person should be between 3 and 5 [27] while the optimum air volume for music (opera) halls should be between $6-8 \mathrm{~m}^{3} /$ person [20].

The Engineering auditorium (CE) which was designed to a capacity of 870 seats has a $6.2 \mathrm{~m}^{3} /$ person. This is within the recommended optimum air volume per person for music halls. The Great Hall, also a multi-purpose auditorium has an average air volume per person of 4.1. This is within the ideal range for a hall that has a multipurpose function with speech (conferences) being the least reverberant use of the auditorium.

The KSB auditorium which is a speech auditorium, however, has an air volume per person of 12.2 which far exceeds the optimum recommendation for a speech hall which is $3-5 \mathrm{~m}^{3} /$ person. This is likely to cause a longer than optimum reverberation time unless other acoustic design interventions are taken such as the dimensions and material properties of the auditorium boundary surfaces to regulate the reverberation time to optimum levels as suggested by [27]. The CCB auditorium too has an air volume per person of 9.0 which exceeds the optimum guideline for both speech and music.

\subsection{Boundary Surfaces Materials and Dimensions}

Floor. The [3] is of the view that "sloped floors, with level terraces for each row of seating provides proper sightlines and sound lines from the audience to the stage". [7] adds that the floor of an auditorium should have a minimum slope of $8^{\circ}$ whilst that of a lecture-demonstration hall is $15^{\circ}$. The Engineering auditorium has a raked floor with a slope of $17^{\circ}$ which exceeds the minimum slope of $8^{\circ}$ for a general auditorium and is suitable for ensuring good sightlines and sound lines as recommended by [7]. Yet, the KSB auditorium has a floor slope of $2.4^{\circ}$ and a gallery slope of $6.4^{\circ}$ while the CCB has a floor slope of $4.8^{\circ}$ which is less than the ideal slope of $8^{\circ}$. The GH auditorium on the other hand which was also designed for multiple functions including dinners has a flat floor.

Walls: Concave, round and parabolic wall shapes should be avoided because they create undesirable foci. From the study, none of the 4 structures had curved or round walls. 
Ceiling: According to reviewed literature, the ceiling should not be parallel to the floor but should be shaped to direct sound to the seating areas of the auditorium and avoid echoes. With respect to the study, the $\mathrm{CE}, \mathrm{CCB}$, and GH auditoria have convex ceiling panels designed to direct sound to the audience. The KSB auditorium on the other hand had a large single concave suspended ceiling as shown in Figure 8. This is contrary to recommendations by [7], [15] and [24].

\section{Gallery:}

[22] suggests that the angle of the sightline from the balcony (gallery) to the stage should not exceed $30^{\circ}$. From the study, all four auditoria had good sight lines and sound lines. Yet, an area of concern is the quality of sound received by the audience beneath the gallery. Recommended depth to height ratio for galleries in concert halls is 1:1, whilst that for opera and drama is to be 2:1 to avoid acoustic shadows [6] [7] [22] [24]. From the study, the Engineering auditorium had a gallery depth to height ratio of 1:1 while the Great Hall has a gallery depth-height ratio of 1.2:1 which is ideal for proper sound distribution to the audience beneath the gallery with no acoustic shadows. The KSB and CCB halls on the other hand have gallery depth to height ratios of 5:1 and 3:1 respectively. These results far exceed the suggested maximum ratio of 2:1 [22]. The poor ratio in these two halls will lead to acoustic shadows beneath the gallery as shown in Figure 9.

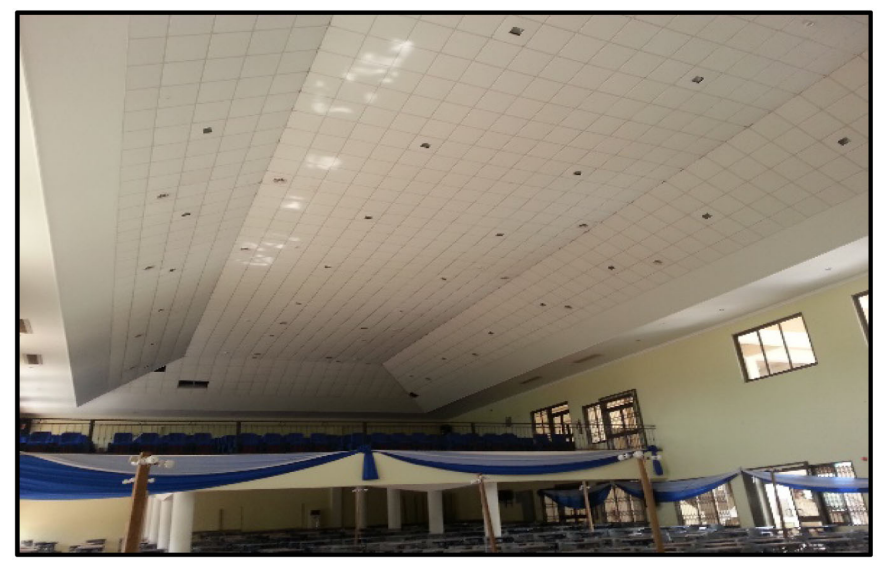

Figure 8. Interior view of the KSB auditorium showing the shape of existing ceiling.

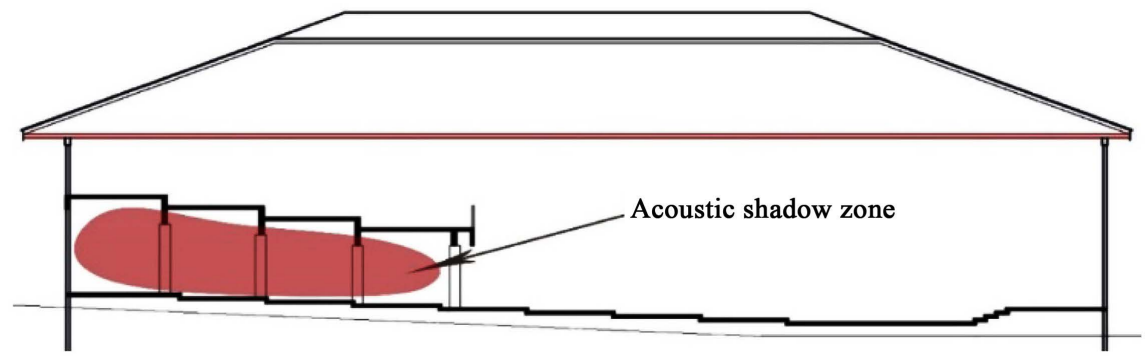

Figure 9. Sectional view of the KSB auditorium showing deep gallery and area of acoustic shadow. 


\section{Materials of the boundary surfaces and Reverberation Time:}

Existing literature reveals that it is advisable for the enclosing surfaces of an auditorium to be made of materials with good acoustic properties to improve the key acoustic performance indicators such as the reverberation time [21] [22]. It is therefore key that materials with high sound absorption coefficients are used. According to [12], the reverberation time for a speech and music auditorium should be between $1.5 \mathrm{~s}$ and $2.5 \mathrm{~s}$. This is highly dependent on the volume of the room and the absorption coefficients of the enclosing surface materials.

Calculating the reverberation time using Sabine's formulae manually, and with the Ecophon Acoustic calculation tool for the existing and improved situation for the various halls resulted in the results shown in Table 7.

The reverberation time for the engineering auditorium (CE) using the Sabine formula resulted in 1.15 seconds. This varied slightly from the results obtained using the Ecophon acoustic calculator with a difference of 0.32 .

According to [10], optimum reverberation time for speech halls with a volume of $10,000 \mathrm{~m}^{3}$ to $20,000 \mathrm{~m}^{3}$ as 0.85 seconds to 1.1 seconds. Hence, improvements were made by changing the floor material from tiles (absorption coefficient of 0.03 ) to carpet (absorption coefficient of 0.25 ) on concrete floor and the wall cladding material from timber panelling (absorption coefficient of 0.04 ) to glass wool panel (absorption coefficient of 1.0) which resulted in an improved reverberation time of 0.84 seconds.

Furthermore, having considered the various absorption coefficients of the concrete masonry enclosing wall, the glass windows, the heavy curtains, the furniture, floor, soffit and the ceiling material of the KSB auditorium which has a volume of $11,585.28 \mathrm{~m}^{3}$, manual calculations resulted in a reverberation time of 2.7 seconds while the Ecophon calculator gave a reverberation time of $1.73 \mathrm{sec}-$ onds. The difference of $1 \mathrm{~s}$ was because of the improvement assumptions made on the ceiling material in the software (Ecophon master matrix $40 \mathrm{~mm}, 85 \%$ absorption instead of the existing PVC foam boards, $4 \%$ absorption). However, the value obtained does not meet the optimum reverberation time of 0.8 seconds to 1.1 seconds for KSB auditorium which has a volume of $11,585.28 \mathrm{~m}^{3}$. Improvements were therefore made in the software by the addition of acoustic wall panels to cover about $70 \%$ of the existing concrete masonry stage (front) wall and the rear wall. The panel system had an absorption coefficient of 1.0 and hence the acoustic improvements made to the walls resulted in an improved reverberation time of 0.9 seconds.

Table 7. Summary of calculated and improved reverberation time (RT).

\begin{tabular}{cccccccc}
\hline Hall & Vol. $\left(\mathrm{m}^{3}\right)$ & Capacity & $\begin{array}{c}\text { Air Vol } \\
\left(\mathrm{m}^{3} \text { /person) }\right.\end{array}$ & $\begin{array}{c}\text { Gallery } \\
\mathrm{d}: \mathrm{h} \text { ratio }\end{array}$ & $\begin{array}{c}\text { RT } \\
\text { Manual @ 500 Hz }\end{array}$ & $\begin{array}{c}\text { RT } \\
\text { (Ecophon@ 500 Hz) }\end{array}$ & $\begin{array}{c}\text { Ecophon } \\
\text { improvement }\end{array}$ \\
\hline CE & 5357.24 & 870 & 6.2 & $1: 1$ & 1.15 & 1.47 & 0.84 \\
KSB & $11,585.28$ & 950 & 12.2 & $5: 1$ & 2.7 & 1.73 & 0.9 \\
GH & 6558.75 & 1600 & $4: 1$ & $1.2: 1$ & 1.89 & 1.92 & 0.89 \\
CCB & $13,169.52$ & 1200 & 9.1 & $3: 1$ & 2.23 & 2.23 & 1.73 \\
\hline
\end{tabular}


The reverberation time for the GH auditorium was also calculated manually using the Sabine formula and a reverberation time of 1.89 seconds was obtained. This varied slightly from the results obtained using the Ecophon acoustic calculator, 1.92 seconds with a difference of 0.03 .

According to [10], optimum reverberation time for amplified music in music halls with volume of $6500 \mathrm{~m}^{3}$ should be at least 1.2 seconds and for speech 0.80 seconds to 0.85 seconds. However, for multipurpose auditoriums, reverberation time may not be enough for music but may be excessive for spoken word. Hence, there verberation time for a multi-purpose auditorium should be short enough for the least reverberant use. Improvements were therefore made in the software calculation by the change in the ceiling material to a more absorbent ceiling system (absorption coefficient of 0.95 ) and addition of acoustic wall panels (absorption coefficient of 1.0). This resulted in an improved reverberation time from 1.9 seconds to 1.07 seconds. According to [23], in auditorium spaces that have only vertical walls, the main surface where sound absorption is predominantly concentrated is the floor. Therefore, an improvement in the floor material resulted in a substantive improvement of the reverb time.

\section{Conclusion and Recommendations}

\subsection{Conclusion}

The focus of the study was to review strategies on auditoria design, see how they are being applied to buildings on KNUST campus, and suggest improvement on the performance of the halls. The paper revealed that the strategies involved in auditorium design are shape, volume, surface boundary dimensions and materials, stage, seating, foyers and sightlines. These parameters are grouped under acoustical, functional and programmatic parameters. The study shows that engineering auditorium and Great Hall met the optimum requirement for air volume per person. However, the KSB and CCB auditorium had volume which exceeded the standard requirement for both speech and music auditorium. Therefore, the calculated reverberation time for the KSB and CCB far exceeded the recommended reverberation time for auditoriums with similar volumes and functions.

Additionally, the study also confirmed that the volume of an auditorium is not the only factor that affects the reverberation time. The characteristic of the boundary surfaces is a great determinant of the reverberation time.

With respect to ensuring speech intelligibility of auditorium spaces, based on recommendations, acoustical flaws such as echoes, long-delayed reflections and acoustical shadows should be avoided by the design while providing for appropriate reverberation time based on the volume and function of the auditorium. Specifically, the ideal ratio of an auditorium's height to width to length should be between 1:1.14:1.39 and 1:1.60:2.33 to avoid long delayed reflections. Also, the design of gallery in the auditorium should be according to the depth-height ratio not more than 2:1 to avoid acoustical shadow regions beneath the gallery. Fi- 
nally, the boundary surfaces of the auditorium should have high absorption coefficients so as to prevent unwanted sound deflections and echoes.

\subsection{Recommendations}

From the study, an improvement in materials with better absorption coefficient resulted in a substantial improvement in the reverberation time for all 4 auditoria studied. A rehabilitation effort should be undertaken to improve the performance of the halls. Moreover, Architects and Architecture schools are to focus more on the standards and recommendations to design comfortable auditoria.

\section{Acknowledgements}

The authors are grateful to the KNUST Development office for providing the needed information on special details of the auditoria studied.

\section{Conflicts of Interest}

The authors declare no conflicts of interest regarding the publication of this paper.

\section{References}

[1] Topa, M.D., Toma, N., Kirei, B.S., Saracut, I. and Farina, A. (2012) Experimental Acoustic Evaluation of an Auditorium. Advances in Acoustics and Vibration, 2012, Article ID: 868247. https://doi.org/10.1155/2012/868247

[2] Noxon, A. (2002) Acoustics Science Corporation (ASC): Auditorium Acoustics. http://www.acousticsciences.com/media/articles/auditorium-acoustics-104

[3] Whole Building Design Guide Staff, WBDG (2009) Auditoria. http://www.wbdg.org/design/auditorium.php

[4] Elliot, W. (2007) Achieving Excellent Auditorium Acoustics. http://www.christianschoolproducts.com/articles

[5] Grebnicka, B. (2013) Acoustical Design. Bachelor of Architectural Technology and Construction Management. VIA University College, Denmark.

[6] Yin, H.W. and Kwok, S.W. (1986) Auditorium Acoustic Design. http://www.worldcat.org/title/auditorium-acoustic-design-hong-kong-academy-for -performing-arts/oclc/53806529

[7] Zaki, M. (2014) Acoustical Design Consideration for Auditorium, Lecture Hall, Recording Studio. https://www.slideshare.net/mominzaki/auditorium-acoustics-33230112

[8] Escobar, V.G. and Morillas, J.M.B. (2011) Analysis of Acoustical Characteristics and Some Recommendations for Different Educational Rooms. Archives of Acoustics Archives of Acoustics, 36, 741-759. https://doi.org/10.2478/v10168-011-0050-8

[9] Hodgson, M. (2004) Case-Study Evaluations of the Acoustical Designs of Renovated University Classrooms. Applied Acoustics, 65, 69-89. https://doi.org/10.1016/S0003-682X(03)00108-7

[10] Ellison, S. and Schwenke, R. (2010) The Case for Widely Variable Acoustics. Proceedings International Symposium on Room Acoustics, Melbourne, 29-31 August 2010, 1-4. 
[11] Wróblewska, D. (2010) Acoustical Standards Used in Design of School Spaces. Acta Physica Polonica A, 118, 186-189. https://doi.org/10.12693/APhysPolA.118.186

[12] Barron, M. (2010) Auditorium Acoustics and Architectural Design. Spon Press, New York.

[13] Hetherington, R. and Oldham, D. (2006) The Generation and Three-Dimensional Display of Auditorium Forms by Means of the www. 13th International Congress on Sound and Vibration, Vienna, 2-6 July 2006, 2354-2361.

[14] Mahalingham, G. (1998) The Algorithmic Auditorium: A Computational Model for Auditorium Design. http://papers.cumincad.org/data/works/att/cd26.content.pdf

[15] Kamlet, R. (2005) Acoustics and Sound Systems in Architectural Design. AIA Continuing Education Series.

https://docplayer.net/11237671-Acoustics-and-sound-systems-in-architectural-desi gn.html

[16] Kowaltowski, D., Mikami, S.A., Bertoli, S.R. and Soler, C. (2006) Design Evaluation and Strategies, the Case of University Auditoriums. Proceedings Conference on Passive and Low Energy Architecture, Geneva, 6-8 September 2006, 631-637. http://www.unige.ch/cuepe/html/plea2006/Vol2/PLEA2006 PAPER139.pdf

[17] Saint-Gobain Ecophan (2002) Don't Limit Your Senses: Sound and the Learning Environment. Saint-Gobain Ecophan AB, Hyllinge.

[18] Farizzah, I. (2014) General Design Consideration of Room Acoustic [Online]. https://www.academia.edu/4857140

[19] Ilangovan, K. (2009) Acoustics of Auditorium. http://fascinatingphysics.blogspot.com/2009/08/acoustics-of-auditorium.html

[20] Neufert Ernst \& Peter (2001) Architect's Data. 3rd Edition, Oxford Brookes University, Oxford.

[21] Appleton, I. and Fischer, S. (2008) Metric Handbook Planning and Residential Data. 3rd Edition, Architectural Press, Oxford.

[22] Pickark, K. (2003) Architects' Handbook. Blackwell Science Ltd., Oxford.

[23] Barron, M. and Kissner, S. (2017) A Possible Acoustic Design Approach for Multi-Purpose Auditoria Suitable for Both Speech and Music. Applied Acoustics, 115, 42-49. https://doi.org/10.1016/j.apacoust.2016.08.018

[24] Kimeu, M. (2014) Acoustics Design in Auditoria: The Case of the LRC at CUEA. http://erepository.uonbi.ac.ke/bitstream/handle/11295/80960/Musau Acoustics\%20 design $\% 20$ in $\% 20$ auditoria $\% 3 \mathrm{a} \% 20$ the $\% 20$ case $\% 20$ of $\% 20$ the $\% 20$ LRC $\% 20$ at $\% 20$ CUEA pdf? sequence $=1$ \&isAllowed $=y$

[25] Prodi, N. and Pompoli, R. (2016) Acoustics in the Restoration of Italian Historical Opera Houses: A Review. Journal of Cultural Heritage, 21, 915-921. https://doi.org/10.1016/j.culher.2016.03.004

[26] Loh, M.J. (2014) Base Theatre Design. https://www.wbdg.org/FFC/AF/AFDG/ARCHIVES/basetheater.pdf

[27] Elkhateeb, A.A. (2012) The Acoustical Design of the New Lecture Auditorium, Faculty of Law, Ain Shams University. Ain Shams Engineering Journal, 3, 219-235. https://doi.org/10.1016/j.asej.2012.04.005 